\title{
Low dose cyclosporin A versus pulsed cyclophosphamide in Behçet's syndrome: a single masked trial
}

Yilmaz Özyazgan, Sebahattin Yurdakul, Hasan Yazici, Binnur Tüzün, Aydin İşçimen, Yalçin Tüzün, Turgay Aktunç, Halit Pazarli, Vedat Hamuryudan, Asuman Müftüoğlu ceding 6 months. Patients who had end stage disease, with mainly irreversible retinal damage and blindness preventing their evaluation, were excluded. All patients fulfilled the recently reported international diagnostic criteria. ${ }^{17}$

At the beginning of the trial the patients were assigned alternatively to receive either cyclosporin A solution $5 \mathrm{mg} / \mathrm{kg} /$ day or monthly intravenous boluses of $1000 \mathrm{mg}$ of cyclophosphamide after an explanation of the investigative nature of the study and obtaining their consent. However they were free to choose either treatment modality irrespective of their initial allocation. The mean weight of the patients to receive cyclosporin $A$ was 66.4 (SD 10.4) $\mathrm{kg}$ and the mean weight of those to receive cyclophosphamide was $64 \cdot 0$ (SD 9.7) $\mathrm{kg}$.

Cyclosporin A solution was given by mouth in two divided doses. All patients were required to attend the clinic once a week during the first month and monthly thereafter. Measurements of body weight, pulse rate, blood pressure, serum creatinine, and serum cyclosporin A levels were performed at each visit and total blood counts, liver function tests (ALT, AST, bilirubin, and alkaline phosphatase), and urinalyses every 3 months. Each month $1000 \mathrm{mg}$ doses of cyclophosphamide were given intravenously in 1 litre of $5 \%$ dextrose solution over 1 hour. Total blood and platelet counts were done on each visit before pulsed cyclophosphamide therapy.

A full ophthalmological evaluation was performed by the same observer (YÖ) who was initially masked to the outcome of drug allocation. Special attention was given to visual acuity and the occurrence of eye attacks. The visual acuity in evaluating the results was expressed by taking the mean of the numerators for each eye on a 0-10 Snellen chart. A new attack was defined as an increase or development of inflammatory cells in anterior chamber, flare, vitreous haze, all graded on a $0-4+$ scale. Furthermore, the mere presence or absence of retinal vasculitis, macular oedema, vascular sheathing, venous occlusion, and vitreous condensation were also recorded at each visit. Of these parameters the emergence of macular oedema or of retinal vasculitis was also interpreted as an indicator of a new attack. Dermatological evaluation was graded as 'worse' $(-1)$, 'same' $(0)$, 'better' $(+1)$, both by the patient and the dermatologist (again single masked). An internist (SY) ran the study as the primary care physician and made the necessary dose adjustments. No patient had been taking immunosuppressive drugs during the preceding 6 months of entry to the trial. However there were three patients taking steroids.
Patients and methods

Twenty three Behçet's patients with Behçet's Syndrome Outpatient Clinic at this clinic is described in detail elsewhere. ${ }^{\prime}$ All patients had bilateral severe uveitis with mainly posterior involvement and at least three ocular disease exacerbations (attacks) within the pre- 
One patient was in the cyclosporin A group taking prednisolone $20 \mathrm{mg}$ every other day and two were in the cyclophosphamide group, one using $10 \mathrm{mg}$ and the other $5 \mathrm{mg} /$ day of prednisolone.

The study was initially planned to last 24 months. Seventeen months from the entry of the first and 7 months after the last patient the trial was unmasked due to the apparent beneficial affects of cyclosporin A observed by the nonmasked members of the study group and similar reports of investigators from other centres. ${ }^{16}$ However during the open phase the formal monthly evaluations of the patients were carried out up to 24 months.

\section{Results}

Table 1 shows the demographic characteristics, the disease duration, and severity of eye disease at the time of entry into the trial. All patients had bilateral eye disease. It was noted that all 12 patients using cyclosporin $\mathrm{A}$ were males as the females refused to use cyclosporin A because of risk of potential hirsutism. There were however six males and five females in the cyclophosphamide group. The mean age at entry, duration of eye disease, and the mean visual acuity were similar between the two groups. There were no statistically significant differences in the scores of inflammatory cells and flare in the anterior chamber and vitreous haze between the two groups at the onset of the trial.

The trial was unmasked after a mean of $12 \cdot 30$ (SD 2.36) months for the patients in the cyclosporin A group and $9 \cdot 80$ (SD 3.42) months for those in the cyclophosphamide group $(t=1.90$, $0 \cdot 10>p>0 \cdot 05)$. During this time two patients from the cyclosporin A group were lost from the trial. One was at month 9 when he developed hepatitis $B$ and had to be withdrawn. The second

Table 1 Patient characteristics

\begin{tabular}{llllll}
\hline & Number & $\begin{array}{l}\text { Malel } \\
\text { female }\end{array}$ & $\begin{array}{l}\text { Age at entry } \\
\text { (years) }\end{array}$ & $\begin{array}{l}\text { Duration of eye } \\
\text { disease (years) }\end{array}$ & $\begin{array}{l}\text { Mean visual acuity } \\
\text { at entry }\end{array}$ \\
\hline Cyclosporin A & 12 & $12 / 0$ & $29(6)^{\star}(15-39) \dagger$ & $2 \cdot 64(1 \cdot 58)(1-5 \cdot 5)$ & $4 \cdot 46(2 \cdot 96)$ \\
Cyclophosphamide & 11 & $6 / 5$ & $32(6)(25-41)$ & $2 \cdot 39(2 \cdot 37)(0 \cdot 5-8)$ & $4 \cdot 77(2 \cdot 65)$ \\
\hline
\end{tabular}

*SD in parenthesis.

tRange.

Table 2 Visual acuity

\begin{tabular}{lllll}
\hline & At entry & At 6 months & $\begin{array}{l}\text { At the time of unmasking } \\
\text { of the trial }\end{array}$ & At 24 months \\
\hline Cyclosporin A & $\begin{array}{l}4 \cdot 46(2 \cdot 96) \dagger \\
(n=12)\end{array}$ & $\begin{array}{l}6 \cdot 82(2 \cdot 98) \ddagger \\
(n=11)\end{array}$ & $\begin{array}{l}4 \cdot 75(4 \cdot 84) \\
(n=10)\end{array}$ & $\begin{array}{l}4 \cdot 50(2 \cdot 94) \\
(n=8)\end{array}$ \\
Cyclophosphamide & $\begin{array}{l}4 \cdot 77(2 \cdot 65) \\
(n=11)\end{array}$ & $\begin{array}{l}4 \cdot 14(3 \cdot 09) \\
(n=11)\end{array}$ & $\begin{array}{l}3 \cdot 95(2 \cdot 30) \\
(n=10)\end{array}$ & not comparable \\
& $(n=11)$ & \\
\hline
\end{tabular}

*See text for duration of the masked periods for each group.

$\dagger S D$ in parenthesis.

$\ddagger t=5 \cdot 47, p<0 \cdot 001$ versus visual acuity at entry (paired $t$ test).

Table 3 Number of ocular attacks per patient per month

\begin{tabular}{|c|c|c|c|}
\hline & Up to 6 months & $\begin{array}{l}\text { From } 6 \text { months to the time } \\
\text { of unmasking of the trial }\end{array}$ & $\begin{array}{l}\text { From the time of unmasking of } \\
\text { the trial to } 24 \text { months }\end{array}$ \\
\hline Cyclosporin A & $\begin{array}{l}0.48(0.28)^{\star} \dagger \\
(n=11)\end{array}$ & $\begin{array}{l}0.49(0.52) \\
(n=10)\end{array}$ & $\begin{array}{l}0.51(0.46) \\
(n=8)\end{array}$ \\
\hline Cyclophosphamide & $\begin{array}{l}0 \cdot 62(0 \cdot 22) \dagger \\
(n=11)\end{array}$ & $\begin{array}{l}0.60(0 \cdot 51) \\
(n=10)\end{array}$ & not comparable \\
\hline
\end{tabular}

$\star S D$ in parenthesis

$t=1 \cdot 30, p>0 \cdot 02$. one was a no-show after 3 months. During the same time there was one loss at month 11 from the cyclophosphamide group for unknown reasons. After the trial was unmasked there were two further losses from the cyclosporin A group at months 11 and 21 , again without apparent causes.

Only four patients from the cyclophosphamide group completed the 24 months continuing to use bolus cyclophosphamide. Of the remaining six patients four were switched to cyclosporin A, one to oral cyclophosphamide, and one to weekly doses of methotrexate.

The mean dose of cyclosporin A which could be used was $4 \cdot 89$ (SD 0.54) $\mathrm{mg} / \mathrm{kg} /$ day during the first 6 months of the masked period and 4.49 (SD 0.94$) \mathrm{mg} / \mathrm{kg} /$ day during the rest of the trial $(t=1 \cdot 60, p>0 \cdot 10)$. The mean plasma level of cyclosporin A was 131.20 (SD 13.80) $\mathrm{ng} / \mathrm{ml}$ during the masked phase. Plasma levels were not routinely done during the open phase. Among the eight patients who completed the full 24 months using cyclosporin the mean serum creatinine level at the time of entry was 70 (SD 7.01) $\mu \mathrm{mol} /$ litre and 79 (SD 17) $\mu \mathrm{mol} /$ litre at their last visit $(t=2 \cdot 02,0 \cdot 10>p>0.05)$. No patient had to be withdrawn due to any form of drug toxicity.

The alternate day steroid that was being used in one patient in the cyclosporin A group was gradually tapered down and was stopped at 9 months. This was the same patient that had to be withdrawn because of hepatitis $B$. The steroid use in two patients in the cyclophosphamide group was stopped after the first month.

Table 2 depicts the mean visual acuity at four different points in the trial and shows that visual acuity significantly improved when compared with that observed at entry in the cyclosporin A group at 6 months $(p<0.001)$. This initial improvement however had disappeared by the time the trial was unmasked. The visual acuity among the eight patients continuing to use cyclosporin $A$ at the end of 24 months remained approximately the same as that at the time of unmasking the trial or as that at entry. No statistically significant change in visual acuity among the patients using cyclophosphamide occurred at the three time points, apart from a trend to deterioration at the time of unmasking the trial when compared with that at the time of entry.

As seen in Table 3 although there was a trend for fewer ocular attacks in the cyclosporin A group this did not assume statistical significance for the time intervals assessed.

Statistical analysis of other pathology related to the eye (retinal vasculitis, macular oedema, etc.) was not attempted because of few events in a small number of patients. Although the effect of cyclosporin A and cyclophosphamide on the extraocular manifestations of the disease were also recorded again there were too few events in our small group of patients to perform a formal analysis.

\section{Discussion}

During the initial 6 months the most relevant outcome of eye involvement, the visual acuity, fared significantly better among the cyclosporin 
A users compared with those using cyclophosphamide. Even though only a small number of patients could be studied it was possible to demonstrate this effect. The 6 month interval was arbitrarily chosen as a convenient time span when the effect of the two medications could be compared between the maximum number of patients from each group. Furthermore in the allocation of patients to the treatment groups there was a definite bias towards females among the cyclophosphamide users. This was mainly due to patient refusal of cyclosporin A because of risk of potential hirsutism. ${ }^{14}$ Behçets syndrome runs a more severe course in the male and this is also true for eye disease. ${ }^{1}$ Thus the more beneficial effect of cyclosporin A compared with cyclophosphamide would perhaps have been more apparent had there been a more even sex distribution of the patients.

The long term effect of cyclosporin A on visual acuity as observed in this study was somewhat disheartening especially in the light of the favourable effect noted during the early phase. It can be said that the visual acuity during the open phase cannot legitimately be compared with that in the masked phase because of possible observer bias. However as noted in Table 2 the trend for dampening of the beneficial effect of cyclosporin A begins before the time when the code is revealed. On the other hand the preservation of the mean visual acuity among the eight patients who completed the full 24 months can be taken as a clue to the efficacy of cyclosporin $A$ in the treatment of eye disease in Behçet's syndrome. In a placebo controlled study of azathioprine recently reported by our group ${ }^{18}$ the mean visual acuity had significantly deteriorated among the placebo users after 24 months. It is to be noted that in the azathioprine study ${ }^{18}$ the patients had not been specifically selected for active eye disease as was the case in the current study.

We believe that cyclosporin $A$ is a useful and, currently, perhaps the most effective agent for the treatment of eye disease in Behçet's syndrome. This seems especially true for its short term use. Its potential usefulness over longer periods however needs to be further elucidated by carefully conducted studies in greater number of patients using acceptable doses.

We thank the Sandoz company for their supply of cyclosporin A (Sandimmun) and Mrs Emine Öztürk for her secretarial assistance.

1 Yazıcı H, Tüzün Y, Pazarlı $H$, et al. Influence of age of onset and patient's sex on the prevalence and severity of manifestation of Behçet's syndrome. Ann Rheum Dis 1984; 43: 783-9.

2 Nussenblatt RB, Palestine AG, Clan CC, et al. Effectiveness of cyclosporin therapy for Behçet's disease. Arthritis Rheum 1985; 28 : 671-9.

3 LeHoang $P$, Fontaine $M$. Treatment of noninfectious inflammatory disorders of the eye with ciclosporin. In: Schindler $\mathrm{R}$, ed. Ciclosporin in Autoimmune Diseases. Berlin: SpringerVerlag, 1985: 137-8.

4 Wechsler B, Mertani EB, LeHoang P, et al. Cyclosporin A is effective but not safe, in the management of Behcet's disease (Letter). Arthritis Rheum 1986; 29: 574.

5 Tabbara KF, Chavis P, Antonios S. Cyclosporin effects on retinal vasculitis in Behcet's disease. In: Lehner T, Barnes retinal vasculitis in Behçet' Recent Advances in Behçet's Disease. London: Royal CG, eds. Recent Advances in Behçet's Disease. Lond

6 Hayashi K, Yamashita K, Nagagawa K, Masuda K. Longterm treatment of severe Behçet's disease with cyclosporin A. In: Lehner T, Barnes CG, eds. Recent Advances in Behçet's Disease. London: Royal Society of Medicine Services Limited, 1986: 347.

7 Svenson K, Bohman SO, Halgren R. Renal interstitial fibrosis and vascular changes: occurrence in patients with autoimmune diseases treated with cyclosporine. Arch Intern Med 1986; 146: 2007-10.

8 Müftüoğlu AU, Parzarl H, Yurdakul S, et al. Short term cyclosporin A treatment of Behçet's disease. Brf Ophthalmol 1987; 71: 387-90.

9 Binder AI, Graham EM, Sanders MD, Dinning W, James DG, Denman AM. Cyclosporin A in the treatment of severe DG, Denman AM. Cyclosporin A in the treatment

10 BenEzra D, Cohen E, Chajek T, et al. Evaluation of conventional therapy versus cyclosporine A in Behçet's syndrome. Transplant Proc 1988; 3: 136-43.

11 BenEzra D, Cohen E, Rakotomalala M, et al. Treatment of endogenous uveitis with cyclosporine A. Transplant Proc 1988; 20: 122-7.

12 Nussenblatt RB, Palestine AG, Rock AH, Scher I, Wacker WB, Grey $I$. Treatment of intraocular inflammatory disease with cyclosporin A. Lancet 1983; i: 235-8.

13 Masuda K, Nakajima A, Urayama A, Nakae K, et al. Doublemasked trial of cyclosporin versus colchicine and long-term open study of cyclosporin in Behçet's disease. Lancet 1989; i: 1093-6.

14 Kahan BD. Drug therapy: cyclosporine. N Engl f Med 1989; 321: 1725-38.

15 Tugwell P, Bombardier C, Gent M, et al. Low-dose cyclosporin versus placebo in patients with rheumatoid arthritis. sporin versus placebo in pate
Lancet 1990; 335: 1051-5.

16 BenEzra D, Nussenblatt RB, Timonen P. Optimal use of Sandimmun in endogenous uveitis. Berlin: Springer Verlag, 1988

17 International Study Group for Behçet's Disease. Criteria for diagnosis of Behçet's disease. Lancet 1990; 335: 1078-80

18 Yazıcı H, Pazarlı H, Barnes CG, et al. A controlled trial of azathioprine in Behçet's syndrome. N Engl f Med 1990; 322: $281-5$. 